\title{
Medical-Biological, Socio-Economic and Environmental-Hygienic Aspects of Nutrition of the Population in Some Regions of Russia
}

\author{
Dotsenko VA*1, Bashmakov VP2 and Mosiychuk LV $^{3}$ \\ ${ }^{1}$ Chief nutritionist, Russia \\ ${ }^{2}$ Associate professor of a physical education of the Saint-Petersburg institute of the state cinema and television, Russia \\ ${ }^{3}$ Saint-Petersburg, Russia \\ *Corresponding author: Dotsenko VA, Chief nutritionist, Health Committee of Government of Saint-Petersburg, Russia
}

\begin{abstract}
ARTICLE INFO
Received: 㓞 April 25, 2019

Published: 幽 May 06, 2019

Citation: Dotsenko VA, Bashmakov VP, Mosiychuk LV. Medical-Biological, Socio-Economic and Environmental-Hygienic Aspects of Nutrition of the Population in Some Regions of Russia. Biomed J Sci \& Tech Res 17(5)-2019. BJSTR. MS.ID.003053.
\end{abstract}

Keywords: Nutrition Assessment; Population; Body Mass Index; Obesity; Food Consumption; Age; Sex; Income; Education

\author{
ABSTRACT
}

Medical-biological and socio-economic problems of population nutrition are presented. The nutrition regime and its multiplicity of 1200 Saint-Petersburg residents over 18 years (674 women, 526 men) were assessed taking into account gender, age, anthropometry data, income level, education and comparing the data with studies of nutrition status in other regions of the Russian Federation. Almost half of Saint-Petersburg residents have deviations of the body mass index in the direction of its increase. Thus, overweight was found in $28.6 \%$, and obesity in $20.7 \%$ of Saint-Petersburg residents accordingly. Women are more likely to be obese (23.5\%) than men (17.1\%). Among the age groups, pensioners are the most overweight and obese (63.6\%). 3.2\% of Saint-Petersburg residents suffer from low body weight (hypotrophy). In this case, women are more likely (4.9\%) to suffer from hypotrophy than men $(0.9 \%)$. Almost half $(49.3 \%)$ of the citizens eat food without salt or with a small amount of it, in addition, the unpopularity of the use of iodized salt is noted. Most of Saint-Petersburg residents said that their diet of fruits and vegetables are present almost daily, but the volume of their consumption is insufficient.

Consumption of fats and sweets is minimal in low-income groups. In the weekly diet fats and sweets are more often present in a group of Saint-Petersburg residents with a high level of income compared to low and middle income (45\% vs. 30.5\% - 35.9\%). Also, in high-income groups less likely to abandon the consumption of dairy products $19.7 \%$ vs. $15.7 \%-16.7 \%$ ). Young people are less likely to refuse the use of dairy products, as well as pasta, cereals, bread and potatoes. The vast majority $(75.3 \%)$ of citizens believe that poor nutrition is harmful and can cause serious diseases. Women $(78.2 \%$ against $71.7 \%$ for men), young people $(82.2 \%$ against $72.5 \%-73.8 \%$ in other groups), as well as Saint-Petersburg residents with higher education $(77.7 \%$ against $70.6 \%$ for people without higher education) are more convinced of this. The prospects of the organization of environmental-hygienic concept of a healthy balanced diet of the person are discussed.

\section{Introduction}

The state policy of the Russian Federation in the field of healthy nutrition of the population is a set of measures aimed at creating conditions that ensure satisfaction in accordance with the requirements of medical science of the needs of different groups of the population in a healthy diet, taking into account their traditions, habits and socio - economic situation [1]. Most of the Russian regions have established programmes aimed at improving the nutritional structure of the population in the region, as well as the establishment of health food centres in four Federal districts and 26 constituent entities of the Russian Federation. Since 2009, health 
centres have been implementing measures aimed at promoting healthy lifestyles in the population, including reducing the consumption of alcohol and tobacco, as well as reducing morbidity and mortality from the most common diseases. However, despite positive trends in population nutrition, mortality from chronic diseases, the development of which is largely associated with alimentary factor, remains much higher than in most European countries.

The nutrition of the majority of the adult population does not comply with the principles of healthy nutrition due to the consumption of foods containing large amounts of animal fat and simple carbohydrates, lack of vegetables and fruits, fish and seafood, which leads to an increase in overweight and obesity, the prevalence of which over the past 8-9 years has increased from 19 to $23 \%$, increasing the risk of diabetes, cardiovascular diseases and other diseases. A significant part of the working population is deprived of the opportunity to eat rationally during working hours, especially in small and medium-sized enterprises, which negatively affects the health of workers and necessitates the further development of programs to optimize the nutrition of the population. The main tasks of the state policy in the field of healthy nutrition, along with others, include the development and implementation of programs of state monitoring of nutrition and public health on the basis of special studies of individual nutrition, including risk groups, safety and development of widespread alimentary-dependent conditions, strengthening the promotion of healthy nutrition, including using the media [1].

\section{Methods}

A sociological study of the regime and diet of the citizens of Petersburg was held in Saint-Petersburg information and analytical center in cooperation with the food and nutrition service of the city [2]. Data collection method: standardized telephone interviews using the SATI system. Group: population of Saint-Petersburg 18 years and older, 1200 people ( 674 women, 526 men), quota (by sex and age), the maximum sampling error at the level of $95 \%$ is $\pm 2.9 \%$. The STATISTIKA software package was used for all calculations.

\section{Results and Discussion}

Residents of Saint-Petersburg in their estimates of growth and body weight indicated that almost half (45.6\%) of them have deviations of the body mass index (BMI) from the normal values in the direction of weight gain. So, overweight was at 24.9 per cent and obesity at $20.7 \%$ of Saint-Petersburg residents. An increase in the body mass index from the normal values occurs with an increase in the age of the respondents. Thus, $63.6 \%$ of pensioners are overweight and obese. For them, this problem is 3.5 times more urgent than for young people and 1.3 times more urgent than for socially active persons of mature age. Among pensioners the overweight set at 35.5 percent, and obese for $28.1 \%$. While obesity is higher among women (23.5 \%) than men (17.1\%). As for low body weight (hypotrophy), it was found in $3.2 \%$ of respondents. In this case, hypotrophy is more common in women (4.9\%) than in men (0.9\%). During the survey of Saint-Petersburg residents it was found that half $(49.3 \%)$ of citizens eat food without salt or with a small amount of it. As a rule, they are Saint-Petersburg citizens with higher education.

Men were more likely to choose salty food than women (18.1 $\%$ vs. $13.6 \%$ ). In the older age groups in general increases the consumption of table salt, but iodized salt is not popular among citizens. Citizens are negligent to the presence in their diet of vitamins (both in the form of drugs and as part of food) about one in three stated that they never use them. These products with a certain periodicity in everyday life are more common for women. The influence of age, income and education factors is also evident here. The absolute majority of Saint-Petersburg residents said that their diet contains fruits and vegetables almost daily, but their consumption is insufficient (vegetables - 15\% below the minimum recommended volume). This is consistent with the pessimistic picture of reviews on the consumption of foods enriched with vitamins and other biologically active components of food. Insufficient volumes of consumption of bread products and potatoes and excess - for sugar and confectionery (10\% higher than the maximum recommended volume) were revealed, which is a negative factor in the formation of a balanced diet of citizens.

The correct diet violates a significant part of the population. Thus, more than half of the respondents $(67.0 \%)$ adhere to the orientation on three or four meals a day. $72.2 \%$ of Saint-Petersburg residents start their day with breakfast. At the same time, more than a quarter of respondents (27.8\%) either eat breakfast irregularly or do not eat breakfast at all. In the Samara region, an unfavorable trend of increasing the consumption of fats and sugar from 2010 to 2015 was revealed, while the consumption of vegetables, fruits and berries was lower compared to the allRussian indicators and recommended consumption levels. In food rations $82 \%$ of respondents did not reach the recommended level of vitamins B1 and B2, Niacin - in 37\%, vitamin A - in 47\%, vitamin $\mathrm{C}$ - in $68 \%$, calcium and iron - in 14\% [3,4]. Among women of Saint-Petersburg more (38.9\%) daily consuming fats and sweets than men (32.1\%). The same pattern in relation to milk and milk products: $58.6 \%$ vs $49.6 \%$, slightly more gap in the daily fruit and vegetable consumption: $80.1 \%$ versus $63.5 \%$. In turn, women are less likely than men to use pasta, cereals, bread and potatoes in their daily diet (41.2\% vs. 55.7\%). Pensioners are less likely than Saint-Petersburg residents in other age groups to consume fats and sweets, but are leaders in the daily consumption of pasta, cereals, bread and potatoes, which is associated with their income. Consumption of fats and sweets is minimal in low-income groups. In the weekly diet fats and sweets are more often present in group of Saint-Petersburg residents with a high level of income than with low and middle income (45\% against 30.5\% - 35.9\%). Also, in high-income groups less likely to abandon the consumption of 
dairy products $(9.7 \%$ vs. $15.7 \%-16.7 \%)$. Fats and sweets, as well as pasta, cereals, bread and potatoes are more often present in the daily diet of persons without higher education. Young people are in the first place on the weekly consumption of vegetables and fruits and less likely to refuse the use of dairy products, as well as pasta, cereals, bread and potatoes. Anoshkina NL [5] notes that imbalance of macro-and micronutrients of actual nutrition of girls, deficiency of proteins and energy-intensive products leads to the development of protein syndrome (SBN) and protein-energy deficiency (SBEN).

Signs of somatic form of SBN were found in $11 \%$, and SBEN in $10 \%$ of the examined girls. The specificity of changes in tissue composition was characterized by a decrease in the content of lean and absolute muscle tissue in SBN, and a decrease in the content of all tissues in SBEN. Inadequate, unbalanced diet and monotony of foods have a negative impact on physical development and increase the risk of acute respiratory diseases (ARI). The majority $(75.3 \%)$ of Saint-Petersburg residents believe that poor nutrition is harmful and can cause serious diseases. Women, young people and people with higher education are especially confident in this. In Nizhny Novgorod, when assessing the diet of the population in the age group 18-29 years were found: imbalance between saturated, monounsaturated, polyunsaturated fatty acids, PUFA $\omega-6$ and $\omega-Z$; vitamin and mineral deficiency. In the structure of nutrition of people of mature age with increased body weight with a coefficient of physical activity of 1.4, i.e. mental labor, the share of sausages in the structure of meat products reached $60.7 \%$.

Consumption of fish and dairy products was lower by $9.8 \%$, and vegetables by $40.4 \%$ and fruits by $15.4 \%$ of regulatory needs. Excess fat of animal origin reached $17.1 \%$. In middle-aged people with chronic diseases of the circulatory system, the proportion with increased body weight reached $43.8 \%$, with obesity 1-2 stage $-50.0 \%$. The average weekly daily caloric content of the diet exceeded energy consumption by $8.2 \%$ [6]. Nutrition as an indicator of quality of life is included in the set of objective indicators, while this indicator can have a number of characteristics, depending on the direction of measuring the quality of life. The problem of quality nutrition is part of the broader problem of well-being, the regulation of which remains the content of the social policy of any developed state. The study of the dynamics of diseases due to poor nutrition not only as a medical and biological, but also socioeconomic problems, revealed a category of the population with problems of availability of even a minimum diet due to low income and a narrower group of people with high income, but also with problems in the organization of quality food, accompanied by an excess of fat in the body and as a consequence acquired obesity.

The multiplicity of the diet of a particular person should take into account the types and methods of culinary processing of food. It should also pay attention to the presence of flexible diet (taking into account household and production load), but at the same time it does not mean constant food "on the go". The habit of slow, measured chewing promotes better digestion and assimilation. The volume of food eaten per day, as a rule, ranges from 2.5-3 $\mathrm{kg}$ (depending on the anthropometric size of the person), with 45-50\% of this amount falls on the main meal - lunch. Intervals between meals should not exceed 4-5 hours. Long breaks can lead to overexcitation of the food center, the release of a large amount of active gastric juice, which coming into contact with the mucous membrane of the empty stomach, can have an irritating effect, until inflammation (gastritis). Short intervals between meals are also impractical, because the food taken does not have time to completely digest and assimilate by the time of the next intake, which can lead to a violation of the motor and excretory function of the digestive tract.

A certain time of eating allows the digestive organs to adapt to the established regime and allocate at certain hours a sufficient amount of digestive juices of high activity and rich in enzymes. In any diet, the last meal should be taken 2.5-3 hours before bedtime, because the digestive system needs to rest. Continuous operation of secretory systems causes a decrease in the digesting power of the juice, reduces its separation, leads to overstrain and depletion of the digestive glands. To restore the normal activity of the digestive glands needed 8-10 hours of rest daily. Food motivation and food sensations are associated with joint activity of the hypothalamus and the cerebral cortex. Mediators of energy metabolism (leptin, insulin, etc.), acting on the hypothalamus zone, also affect the limbic system, controlling behavior, emotions, learning, motivation [7]. The state of hunger forms searches and food-producing behavior, and the state of saturation stops eating. The nutritional need is due to metabolic processes in the body, a decrease in the level of nutrients in the blood, which is accompanied by a feeling of hunger and motivation to search for food.

The state of saturation is formed in two stages. The first stage - sensory saturation (feeling of saturation), occurs during meals as a result of the flow of afferent impulses from the receptors of the tongue, pharynx, esophagus and stomach to the center of saturation, which reciprocally inhibits the activity of the center of hunger, which leads to a decrease in hunger. After taking a sufficient amount of food stops eating behavior and food intake. Touch the saturation prevents the flow of excessive quantities of food in the body. The second stage - the stage of metabolic saturation, occurs after 1.5-2 hours from the start of meals, when the blood begins to receive nutrients. Sufficient concentration of nutrients in the blood (monomers: amino acids, monosaccharides - mainly glucose, fatty acids) is captured directly by the relevant receptors of the hypothalamus and vascular receptors, which ensures the maintenance of a previously formed feeling of satiety. Regulatory peptides such as cholecystokinin, somatostatin, bombezin, etc., which reduce food consumption, i.e. participate in the formation of saturation, apparently play an important role in the occurrence of hunger and saturation. 
Increased food motivation and activation of eating behavior cause pentagastrin, oxytocin, etc., which contribute to the formation of hunger. Eating disorders are considered as a class of psychogenically caused behavioral syndromes associated with eating disorders. Among them are nervous anorexia, nervous bulimia, psychogenic overeating, paroxysmal overeating, nervous orthorexia. Eating disorders, characterized by an obsessive desire for the so-called "healthy and proper, clean diet", leads to significant restrictions in the choice of products. For a person with eating disorders, nutrition becomes an idea so valuable that it often leaves no room for other interests and goals. The diet is determined solely by the criteria of "utility", excluding the criteria of taste and nutrition. On "dirty" and "garbage" food the ban regardless of circumstances is put. Psychogenic overeating due to stressful events, such as conflict relations, separation, problems at work, bereavement, accident, childbirth, etc. In fact, this type of eating disorder is the "food addiction" (while anorexia and bulimia of dependence is rather on weight loss) [8].

Food is used, by analogy with alcohol or drugs, to avoid emotional problems and dull painful emotions. Eating disorders is not currently included in the current international classification of diseases (ICD-10), but will be included in the ICD-11, which will be released in 2020. Imposing "standard" standards of beauty of mass media in combination with weak mental stability forms at part of youth a condition of anorexia, the disease which was also not observed among poor groups of the population. Women with food addiction tend to evaluate their own life time as discontinuous and emotionally negative. Their attitude to the present and the future, their life are characterized by disorganization and fragmentation, weak event saturation, the future is characterized by insufficient planning and forethought goals, reducing the depth of life prospects, irrational choice of means of life [9]. The combination of new types of economic behavior has led to the need to determine the quality of life of the population, taking into account new social patterns of economic development, structuring nutrition as one of the main factors [10].

At the heart of modern ideas about healthy nutrition is the concept of optimal nutrition provides for the need to fully meet the needs of the body not only in essential macro-and micronutrients, but also in a number of necessary minors biologically active components of food, the list of which is constantly expanding

Table 1: Classification of food products according to their purpose.

\begin{tabular}{|c|c|c|c|}
\hline \multicolumn{4}{|c|}{ Purpose of Food Products } \\
\hline Plastic & Energetical & Bioregulatory & Appetite stimulating \\
\hline $\begin{array}{l}\text { Meat and meat products. } \\
\text { Fish and fish products. } \\
\text { Milk and dairy products. } \\
\text { Eggs and egg products. }\end{array}$ & $\begin{array}{l}\text { Bakery, pasta and cereal } \\
\text { products. } \\
\text { Confectionery, sugar, honey, etc. } \\
\text { Fats and fat products. }\end{array}$ & $\begin{array}{c}\text { Vegetables, fruits, berries and their juices. } \\
\text { Liver of animals and fish. } \\
\text { Caviar and embryos of plants. } \\
\text { Dietary supplements: nutraceuticals, } \\
\text { parapharmaceuticals. } \\
\text { Probiotics and prebiotics. }\end{array}$ & $\begin{array}{l}\text { Spices (pepper, mustard, bay leaf, etc.). } \\
\text { Spicy vegetables (onion, garlic, parsley, } \\
\text { etc.). } \\
\text { Other flavours. }\end{array}$ \\
\hline
\end{tabular}

[11]. The theory of balanced nutrition is based on the following postulates:

a) Nutrition supports the molecular composition and reimburses energy and plastic expenditure of the organism.

b) The ideal food is considered, in which the intake of nutrients corresponds to their consumption.

c) The intake of nutrients is provided as a result of the destruction of food structures and the absorption of nutrients needed for metabolism, plastic and energy needs of the body.

d) Food consists of several components, different in physiological significance - nutrients, ballast substances (from which it can be purified) and harmful, toxic compounds.

e) The body's metabolism is determined by the level of amino acids, monosaccharides, fatty acids, vitamins and some salts.

f) Food disposal is carried out by the body itself.

g) Many nutrients, capable of absorption and assimilation, are released by enzymatic hydrolysis of complex organic compounds due to the cavity (extracellular) and intracellular digestion.

Food and the environment are two external environmental factors that support life and at the same time connect our body with the environment [12]. The quality and quantity of food and the structure of nutrition determine primarily health, the risks of disease and provide prevention of disease. Progress in food hygiene depends on the economic situation of the population and its health, physical activity, nutritional structure and health status, as well as on new scientific knowledge about the normal ontogenetic development of parents, fetus and offspring to old age, depending on nutrition and the simultaneous development of technologies for safe food production and environmental protection [13]. In human nutrition uses a variety of products that are sources of proteins, fats, carbohydrates, vitamins, minerals and many other biologically active substances with different organoleptic and physiological properties. However, despite the numerous properties, they can be conditionally systematized according to the predominant use in human nutrition (Table 1). Products are divided into natural (vegetables, fruits, berries, nuts, meat, fish, etc.) and artificial, derived from proteins and other naturally occurring nutrients (artificial caviar protein, crab sticks, etc.). 
In artificial products, you can adjust the chemical composition, structure, appearance, smell, taste and other properties, which is important for the creation of special dietary products and therapeutic and preventive nutrition. Currently, there is a classification of food products, based on the account of the General characteristics and features of their use in the diet of the population. Thus, the following groups are distinguished: milk and dairy products; meat and meat products; fish, fish products and seafood; eggs and products of their processing; oilseeds and fat products; grain products; fruits and vegetables; sugar and confectionery products; beverages; dietary supplements. One of the main criteria for the evaluation of food raw materials and food products are indicators of nutritional value, including the content of basic nutrients (proteins, fats, carbohydrates, vitamins, macro-and microelements), and the energy value of products. The ability of food products to meet the physiological needs of man is determined by its nutritional and biological value.

Biological value is usually understood as an indicator of the quality of food protein, reflecting the degree of compliance of its amino acid composition with the needs of the body in amino acids for the synthesis of its own protein. Usually, the biological value of a protein is assessed by the degree of content of essential amino acids in it, by the indicator of pure protein utilization (CHUB), by the protein efficiency coefficient (CAB) and other indicators. The biological value of food can be assessed by the content of essential macro-and microelements and the degree of their assimilation, as well as the presence of biologically active compounds. The consumer value of food is an integral part of the total nutritional value and is characterized mainly by its commercial qualities (organoleptic and tasting indicators), chemical composition and energy value, the degree of digestibility, saturation and monotony, the possibility of expanding the range of dishes, suitability for storage, etc. Ecological and hygienic waste-free technologies of production of dairy, flour, meat-fish, canning and other branches of food industry are necessary for production of products with high food and biological value.

First, it gives a person the opportunity to rationally use the main nutrients as a source of energy and structural components of individual organs and systems of the body. Secondly, it will contribute to the preservation of natural food components, such as dietary fibers, flavoring substances (flavoring, aromatic, color), medicinal pharmacological compounds and other components that are bioregulators and biostimulators of the most important processes of human life. Third, modern technological processes it is possible to achieve the destruction antilibertarian substances specific antagonists ordinary food substances. Fourth, such modern technological processes could achieve the destruction or significant reduction of such pharmacological compounds that have toxic properties for the human body (histamine, serotonin, tyramine, DOPA, phasin, amygdalin, etc.).
Fifth, it is rational to keep in food microorganisms useful for the human body (lactic acid bacteria, food yeast, etc.) which increase the absorption of nutrients, enrich diets with biologically active substances, especially vitamins, and have a beneficial effect on the endoecology (internal ecology) of human intestinal microorganisms, thereby reducing its endogenous intoxication with harmful products of the synthesis of putrefactive microflora. Sixth, it is important to prevent from hygienic positions in the process of storage, technological processing of products and their realization among the population of their secondary pollution by foreign harmful non-food components. Seventh, particularly promising technologies for obtaining healthy food products based on the inclusion of essential nutrients in the "food chain" of ecosystems (enrichment of soil with essential amino acids, enrichment of vitamins and trace elements of pet food, etc.), which will contribute to a better biological adaptation of humans to these vital components of food.

\section{Conclusion}

In conclusion, it should be noted that the current organization of rational nutrition of different groups of the population should be based on the ecological and hygienic concept of healthy human nutrition. This concept is aimed both at the protection of the internal human environment, its "purity", and the normalization of its life processes, which are closely related to the environment, making in nature a single and interconnected ecological system $[13,14]$.

\section{References}

1. (2010) Order of the Government of the Russian Federation of October 25, $2010 \mathrm{~N} 1873-$ - About bases of state policy in the field of healthy food of the population of the Russian Federation until 2020.

2. Saint-Petersburg (2014) Monitoring of prevalence of a healthy lifestyle according to polls: mode and food allowance of Saint-Petersburg residents. Research opinion. Committee on informatization and communication.

3. Sazonova OV (2011) Studying of a condition of the actual food, justification and development of the program of optimization of food of the population of the Samara region. p. 44.

4. Sazonova OV, Gorbachev DO, Nurdina MS (2018) Hygienic characteristic of the actual food of able-bodied population of the Samara region. J Food Questions 87(4): 32-38.

5. Anoshkina NL (2005) Assessment of physical development, the actual food and the food status at persons of youthful age. pp. 173.

6. Kuroptev A.A (2007) Assessment and correction of a food allowance of the population of various age groups. pp. 134.

7. Volkova GE (2011) A feeding behavior, emotional and personal features and mediators of energy balance at patients with obesity. pp. 150 .

8. Rukavishnikov IA (2006) Pathophysiological aspects of disturbance of a feeding behavior (overeating addiction) pp. 116.

9. Shmykova IV (2005) Valuable conditionality of psychological time of women with a food addiction. pp. 191.

10. Sharipov MM (2010) A balanced diet of the population as a component of quality of his life in the conditions of market economy. p. 24.

11. Tutelyan VA (2002) The reference book on dietology. Tutelyan VA, Samsonov MA (Eds.), $3^{\text {rd }}$ (edn.). M Medicine pp. 544. 
12. Zhminchenko VM, Zhminchenko VM Hygiene, Gapparov MMG (2015) Current trends of researches in a nutritsiologiya and Food. J Food Questions 84(1): 4-14.

13. Dotsenko VA (1990) Ekologo-gigiyenichesky concept of food of Person. J Hygiene and sanitation 7: 13-17.

\section{ISSN: 2574-1241}

DOI: 10.26717/BJSTR.2019.17.003053

Dotsenko VA. Biomed J Sci \& Tech Res

(C) (P) This work is licensed under Creative

Submission Link: https://biomedres.us/submit-manuscript.php
14. Dotsenko VA, Vlasova VV, Mosiychuk LV (2019) Quality and safety Foodstuff. J Health and safety 2: 9-21.

BIOMEDICAL
RESEARCHES $\quad \begin{aligned} & \text { Assets of Publishing with us } \\ & \text { - }\end{aligned}$

